\title{
Chronic Opioid Therapy and Preventive Ser- vices in Rural Primary Care: An Oregon Rural Practice-based Research Network Study
}

\author{
David I. Buckley, MD, MPH'1,2,3 \\ James F. Calvert, $M D^{1,2}$ \\ Jodi A. Lapidus, $\mathrm{PbD}^{4}$ \\ Cynthia D. Morris, $\mathrm{PbD}, \mathrm{MPH}^{1,3-5}$ \\ ${ }^{1}$ Oregon Rural Practice-based Research \\ Network, Oregon Health \& Science Uni- \\ versity, Portland, Oregon \\ ${ }^{2}$ Department of Family Medicine, Oregon \\ Health \& Science University, Portland, \\ Oregon \\ ${ }^{3}$ Department of Medical Informatics and \\ Clinical Epidemiology, Oregon Health \& \\ Science University, Portland, Oregon \\ ${ }^{4}$ Department of Public Health and Preven- \\ tive Medicine, Oregon Health \& Science \\ University, Portland, Oregon \\ ${ }^{5}$ Department of Internal Medicine, Oregon \\ Health \& Science University, Portland, \\ Oregon
}

Conflicts of interest: none reported

\section{CORRESPONDING AUTHOR}

David I. Buckley, MD, MPH

Oregon Health \& Science University

Mailcode: FM

3181 SW Sam Jackson Park Rd

Portland, OR 97239

buckleyd@ohsu.edu.

\begin{abstract}
PURPOSE For clinicians, using opioid therapy for chronic noncancer pain (CNCP) often gives rise to a conflict between treating their patients' pain and fears of addiction, diversion of medication, or legal action. Consequent stresses on clinical encounters might adversely affect some elements of clinical care. We evaluated a possible association between chronic opioid therapy (COT) for CNCP and receipt of various preventive services.
\end{abstract}

METHODS We conducted a retrospective cohort study in 7 primary care clinics within the Oregon Rural Practice-based Research Network (ORPRN). Using medical records of 704 patients, aged 35 to 85 years, seen during a 3-year period, we compared the receipt of 4 preventive services between patients on COT for CNCP and patients not on chronic opioid therapy (non-COT). We used multivariate log-binomial regression analyses to estimate the relative risk of receipt of each preventive service.

RESULTS After adjustment for plausible confounders, we found that patients using COT had a statistically significantly lower relative risk (RR) of receipt of cervical cancer screening ( $R R=0.60 ; 95 \%$ confidence interval $[\mathrm{Cl}], 0.47-0.76)$ and colorectal cancer screening $(\mathrm{RR}=0.42 ; 95 \% \mathrm{Cl}, 0.22-0.80)$ when compared with non-COT patients. The RR was reduced, without statistical significance, for lipid screening $(\mathrm{RR}=0.77 ; 95 \% \mathrm{Cl}, 0.54-1.10)$, and not notably reduced for smoking cessation counseling $(\mathrm{RR}=0.95 ; 95 \% \mathrm{Cl}, 0.78-1.15)$.

CONCLUSIONS Patients using COT for CNCP were less likely to receive some preventive services. Research is needed to better understand barriers to and improved methods for providing preventive services for these patients.

Ann Fam Med 2010;8:237-244. doi:10.1370/afm.1114.

\section{INTRODUCTION}

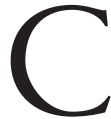

hronic noncancer pain $(\mathrm{CNCP})$ is associated with decreased quality of life, disability, loss of productivity, high direct costs for treatapproximately one-quarter of the US population aged 20 years or older have monthly pain, and roughly $40 \%$ of those have had pain for a year or longer. ${ }^{6}$ Pain is one of the most common reasons that people seek medical attention, ${ }^{7-9}$ most of whom are seen in the primary care setting. ${ }^{19,10}$

Treatment with opioid medication is accepted as appropriate therapy for pain related to cancer and other terminal illnesses. Recent systematic reviews have found, however, the evidence base regarding the long-term efficacy and safety of chronic opioid therapy (COT) for CNCP to be limited and of generally low quality. ${ }^{11,12}$ Use of opioids to treat CNCP is still controversial. ${ }^{11-17}$ Multiple factors underlie this controversy and contribute to dilemmas regarding treatment, including the lack of definitive data on the risks and benefits of opioids for $\mathrm{CNCP}^{11,12,18-20}$; concerns about physi- 
cal dependence, tolerance and addiction ${ }^{21-25}$; concern about possible diversion of opioid medication for other purposes ${ }^{12,15,23,24,26-29}$; and concern about possible sanctions by state and federal regulatory agencies. ${ }^{21,27,28,30-33}$

These concerns may complicate clinical decision making regarding the prescription of opioids $\mathrm{s}^{34,35}$ and may result in extra time demands, failures in the patient-physician relationship, and less time on other activities. ${ }^{7,26}$ Clinicians are increasingly under time constraints during office visits, and it is reasonable to consider that time-consuming activities related to prescribing opioids may detract from other aspects of clinical care, including preventive services. Similarly, stresses on the patient-clinician relationship that derive from the challenges and uncertainties of caring for patients with CNCP on COT may reduce the likelihood of receiving preventive services.

We conducted a study to test the hypothesis that patients who receive chronic opioid therapy (COT) for CNCP in the primary care setting are less likely to receive preventive services than patients who do not receive chronic opioid therapy (non-COT).

\section{METHODS}

\section{Study Design, Setting, and Patients}

We conducted a retrospective cohort study within 7 practices in the Oregon Rural Practice-based Research Network (ORPRN), a network of 49 primary care practices (serving approximately 235,000 patients) located throughout rural Oregon. We enrolled willing practices, purposefully selected to represent each of the 3 major geographical regions served by ORPRN. We compared the receipt of 4 clinical preventive services (screening for cervical cancer, colorectal cancer, and dyslipidemia and counseling for smoking cessation) between patients on COT for CNCP and patients not on COT (non-COT).

We first reviewed the records of patients aged 35 years or older seen in participating clinics during an 8 -week period between mid-March and mid-May 2000 to determine eligibility and establish the 2 comparison groups. We then reviewed records for all patients seen during this period by 1 to 4 randomly selected clinicians at each site. The number of clinicians selected at each site was determined by the total number of clinicians in the practice, with more selected for larger practices.

We defined COT use as either (1) daily opioid medication for at least 6 calendar months during the year 2000; or (2) daily opioid medication for at least 6 calendar months during the year 1999, and at least 6 calendar months during the year 2001, and at least 1 chart entry indicating opioid use during calendar year
2000. To establish the non-COT comparison group, we identified patients within the same practice who did not meet the criteria for COT, and frequency-matched these patients to COT patients by sex and smoking status at a 2:1 ratio.

\section{Data Collection and Definitions of Variables}

Three trained and monitored chart auditors reviewed the medical records of all enrolled study subjects using well-defined chart audit procedures and standardized definitions of study variables. They abstracted data for all variables for the 3 -year observation period of January 1, 2001, to December 31, 2003.

\section{Preventive Services Outcome Variables}

The 4 outcomes of interest were the receipt of 4 recommended preventive services: (1) cervical cancer screening by Papanicolaou (Pap) testing, (2) colorectal cancer screening by at least 1 of 3 methods (fecal occult blood test, sigmoidoscopy, or colonoscopy), (3) serum screening for dyslipidemia, and (4) smoking cessation counseling. We chose these 4 services because each has an A-level recommendation from the US Preventive Services Task Force (USPSTF). In addition, the services represent a variety of patient subgroups and health conditions, and they differ in what they require of patients and clinicians. Each outcome variable was defined as dichotomous (yes or no), indicating whether the particular preventive service was performed at least once during the 3-year period of observation. We confirmed that each test was conducted for screening rather than for diagnosis or assessment of the effectiveness of therapy.

Because each preventive service is recommended based on patient age, sex, smoking status, or a combination thereof, we identified 4 subgroups of study subjects who met the criteria by which each preventive service would ordinarily be recommended. The 4 subgroups for our study were (1) women aged 35 to 65 years (cervical cancer screening), (2) women and men aged 50 years or older (colorectal cancer screening), (3) men aged 35 years or older and women aged 45 years or older (lipid screening), and (4) smokers of any age and either sex (smoking cessation counseling). Individual patients were included in all subgroups for which they fit the criteria.

\section{Other Variables}

Data on a variety of additional variables were abstracted to make comparisons between COT and non-COT patients and to evaluate for possible confounding. Patient medical records were audited for the following variables: age, sex, ethnicity, race, zip code, insurance status and type, primary care clinic, patient's 
primary care clinician, total number of clinic visits during the 3-year observation period, number of visits with patient's primary care clinician, date of last visit during the observation period, diagnosis for which opioids were prescribed, other medical and psychiatric diagnoses (from a list of more than 30 conditions commonly seen in primary care), total number of other diagnoses, history of substance abuse, history and date of a controlled substance contract, and history and date of formal discontinuation as a clinic patient.

\section{Analyses}

We calculated the distributions of demographic, medical, clinic utilization, and other descriptive characteristics between COT and non-COT patients. We used the independent samples $t$ test to compare mean values (continuous variables) and the Pearson $\chi^{2}$ test to compare percentages (categorical variables) between the 2 exposure groups (COT and non-COT). We conducted these analyses for the total study sample and for each of the 4 preventive service subgroups. For each preventive service subgroup, we calculated the percentage of COT and non-COT patients that received the service.

Before conducting regression analyses, we evaluated each variable for its potential as a confounder. Only variables that appeared to be plausible possible confounders were considered in the modeling process. A plausible confounder would first need to satisfy the definitional criterion of being associated with both the exposure (COT status) and the outcome (the particular preventive service) of interest. For this assessment, we used the independent samples $t$ test or the Pearson $\chi^{2}$ test, with a $P$ value of $\leq .05$ as significant. In addition, we included each variable in a bivariate regression model with COT status to determine whether it changed the effect of COT status alone on receipt of the preventive service. We regarded a change in relative risk of approximately $10 \%$ or more as a meaningful basis for considering the variable a plausible confounder.

We fit separate multivariate regression models to estimate the relative risk of receiving each preventive service among COT compared with non-COT patients. We used the prevalence ratio as the measure of effect. When a risk ratio or prevalence ratio is the parameter of interest for a dichotomous outcome, logbinomial regression, which yields a direct measure of relative risk, is a more appropriate method than logistic regression, which estimates odds ratios. ${ }^{36,37}$ We found that some log-binomial models, which may be less numerically stable than logistic models, did not converge. A valid method for addressing this problem is to use the Poisson regression model with robust variance, which approximates the log-binomial maximum likeli- hood estimators. ${ }^{38,39}$ We therefore used this modified Poisson regression for all models.

Different models for each preventive service were compared and assessed for effect size and the significance of covariates in the model. We used the Wald statistic to assess the significance of covariates at the level of $P \leq .05$. We considered the best (final) model for each preventive service outcome to be the one with the greatest number of significant covariates that also contained no nonsignificant covariates. We conducted all analyses using SPSS version 15.0.0 statistical software (SPSS Inc, Chicago, Illinois, 2006). The study was approved by the Institutional Review Board of Oregon Health \& Science University, Portland, Oregon.

\section{RESULTS}

We performed an initial limited data abstraction of 3,314 medical records, in which we identified 263 patients without cancer on COT. Of these, $29 \mathrm{did}$ not meet inclusion criteria, for a total of 234 COT patients included in the study. Of the 3,051 patients identified as non-COT, we evaluated 604, in chronological order of their earliest clinic visit, to identify 470 eligible non-COT patients who were frequency-matched with the COT group. Nearly all of the 29 COT and 134 nonCOT patients excluded from the study were lacking any clinic visits during the 3 -year observation period.

\section{Descriptive Statistics}

The distributions of demographic, medical, clinic utilization, and other descriptive characteristics are displayed in Table 1 . The COT patients were slightly younger and more likely to be white/non-Hispanic. Fewer COT patients had commercial insurance, more had Medicaid, and fewer were uninsured. A higher percentage of COT patients had a history of substance abuse, had 2 or more medical comorbidities, experienced anxiety or depression, or had gastric reflux or a sleep disorder. The COT patients also had a higher mean number of clinic visits, with a slightly higher percentage of visits to their primary clinician, and they were more likely to have voluntarily or involuntarily discontinued being a patient at the clinic.

\section{Results of Regression Modeling}

In Table 2 the results of 3 models are summarized for each preventive service: (1) the unadjusted, univariate model, (2) the best (final) multivariate model, and (3) the multivariate model adjusting only for the 3 covariates common to all 4 final models. Each of the 4 final models included 3 variables in common: age, clinic, and total number of visits. In addition, the final model for colorectal cancer screening also retained the vari- 
Table 1. Social, Demographic, and Clinical Characteristics of Patients by Chronic Opioid Therapy (COT) Status for the Total Sample, Cervical Cancer Screening, and Colorectal Cancer Screening, Chronic Opioid Therapy (COT) Status for Lipid Screening and Smoking Counseling

\begin{tabular}{|c|c|c|c|c|c|c|c|c|c|}
\hline \multirow[b]{2}{*}{ Characteristic } & \multicolumn{3}{|c|}{$\begin{array}{l}\text { Total Sample } \\
\qquad(\mathrm{N}=704)\end{array}$} & \multicolumn{3}{|c|}{$\begin{array}{l}\text { Cervical Cancer Screening } \\
\qquad(n=321)\end{array}$} & \multicolumn{3}{|c|}{$\begin{array}{l}\text { Colorectal Cancer Screening } \\
\qquad(n=425)\end{array}$} \\
\hline & $\begin{array}{c}\text { COT } \\
(n=234)\end{array}$ & $\begin{array}{l}\text { Non-COT } \\
(n=470)\end{array}$ & $\begin{array}{c}P \\
\text { Value }^{a}\end{array}$ & $\begin{array}{c}\text { COT } \\
(n=110)\end{array}$ & $\begin{array}{l}\text { Non-COT } \\
(n=211)\end{array}$ & $\begin{array}{c}P \\
\text { Value }^{a}\end{array}$ & $\begin{array}{c}\text { COT } \\
(n=128)\end{array}$ & $\begin{array}{l}\text { Non-COT } \\
(n=297)\end{array}$ & $\begin{array}{c}P \\
\text { Value }^{a}\end{array}$ \\
\hline Age, mean y & 54.9 & 57.7 & .015 & 48.4 & 48.1 & .752 & 64.7 & 67.0 & .047 \\
\hline Female, \% & 64.1 & 63.4 & .856 & 100.0 & 100.0 & $\mathrm{n} / \mathrm{a}$ & 65.6 & 59.9 & .268 \\
\hline \multicolumn{10}{|l|}{ Ethnicity/race, \% } \\
\hline White, non-Hispanic & 69.7 & 60.0 & .012 & 73.6 & 60.7 & .021 & 71.1 & 62.0 & .070 \\
\hline Other & 4.3 & 7.4 & .105 & 4.5 & 11.8 & .033 & 3.1 & 4.0 & .649 \\
\hline Not specified & 26.1 & 32.6 & .078 & 21.8 & 27.5 & .269 & 25.8 & 34.0 & .094 \\
\hline \multicolumn{10}{|l|}{ Insurance, \% ${ }^{b}$} \\
\hline Commercial & 32.1 & 47.2 & $<.001$ & 26.4 & 38.9 & .025 & 39.8 & 51.5 & .027 \\
\hline Medicaid & 38.0 & 23.6 & $<.001$ & 46.4 & 33.2 & .021 & 30.5 & 16.8 & .002 \\
\hline Medicare & 42.7 & 40.0 & .487 & 22.7 & 15.6 & .117 & 56.3 & 60.3 & .439 \\
\hline Uninsured & 6.4 & 11.5 & .033 & 10.0 & 19.4 & .030 & 5.5 & 6.4 & .714 \\
\hline Other & 11.1 & 6.2 & .021 & 11.8 & 6.2 & .078 & 10.9 & 5.1 & .027 \\
\hline History of substance abuse, \% & 15.0 & 10.0 & .056 & 21.8 & 16.6 & .251 & 8.6 & 5.8 & .282 \\
\hline Smoker, \% & 44.4 & 43.4 & .793 & 50.0 & 55.5 & .353 & 32.0 & 35.7 & .467 \\
\hline Number of comorbidities $\geq 2, \%$ & 85.5 & 78.1 & .020 & 80.9 & 71.1 & .056 & 94.5 & 86.5 & .016 \\
\hline \multicolumn{10}{|l|}{ Select comorbidities, \%c } \\
\hline Anxiety & 13.7 & 8.9 & .053 & 11.8 & 12.8 & .801 & 13.3 & 6.7 & .028 \\
\hline Congestive heart failure & 5.1 & 8.1 & .150 & 0.0 & 3.3 & .053 & 7.8 & 12.1 & .190 \\
\hline Depression & 48.7 & 28.1 & $<.001$ & 59.1 & 38.9 & .001 & 43.0 & 23.2 & $<.001$ \\
\hline GERD/PUD & 28.2 & 19.8 & .012 & 35.5 & 24.6 & .041 & 27.3 & 16.2 & .008 \\
\hline Hepatitis & 5.6 & 2.8 & .064 & 9.1 & 4.3 & .082 & 2.3 & 1.0 & .285 \\
\hline Osteoporosis & 4.7 & 7.0 & .231 & 2.7 & 3.8 & .619 & 6.3 & 10.1 & .202 \\
\hline Sleep disorder & 5.1 & 2.3 & .050 & 6.4 & 2.8 & .129 & 2.3 & 1.3 & .459 \\
\hline Same zip code as clinic, \% & 32.1 & 30.0 & .578 & 30.9 & 38.4 & .185 & 35.9 & 28.3 & .116 \\
\hline Active months, mean No. ${ }^{d}$ & 30.5 & 29.3 & .200 & 29.4 & 29.6 & .906 & 31.0 & 30.2 & .510 \\
\hline Total visits, mean No. & 24.6 & 15.4 & $<.001$ & 25.7 & 14.1 & $<.001$ & 24.6 & 17.4 & $<.001$ \\
\hline Visits with $P C P$, mean \% & 83.0 & 79.2 & .030 & 77.3 & 73.0 & .116 & 84.7 & 82.7 & .340 \\
\hline Record of discontinuation, \%e & 7.7 & 3.0 & .005 & 11.0 & 3.3 & .006 & 6.3 & 2.7 & .081 \\
\hline Preventive service received, $\%^{f}$ & $\mathrm{n} / \mathrm{a}$ & $\mathrm{n} / \mathrm{a}$ & $\mathrm{n} / \mathrm{a}$ & 42.7 & 59.2 & .005 & 7.8 & 13.8 & .081 \\
\hline
\end{tabular}

GERD = gastroesophageal reflux disease; $\mathrm{PUD}=$ peptic ulcer disease; $\mathrm{PCP}=$ primary care physician

Note: Subgroups determined by the recommendation criteria for each preventive service: Papanicolaou testing, women aged 35 to 65 years; colorectal cancer screening all patients aged 50 years or older; lipid screening, men aged 35 years or older and women aged 45 years or older; smoking cessation counseling, all smokers.

a $P$ values are based on comparisons of COT and non-COT patients using the independent samples $t$ test for mean values and the Pearson $\chi^{2}$ test for percentages.

b Because some patients had more than 1 type of insurance, totals are greater than $100 \%$.

Comorbidities listed are those for which a difference $(P \leq .20)$ between COT and non-COT was seen in the total study sample or in at least 1 subgroup.

d Amount of time, in months, between first clinic visit and last clinic visit during the 3-year study period.

e Evidence in the medical record that the patient formally discontinued receiving care at the clinic, initiated by either the patient or the clinic.

${ }^{f}$ For each subgroup, this refers only to the particular preventive service pertaining to that subgroup, and indicates whether the service was received at least once during the 3-year study period.

able for diagnosis of gastroesophageal reflux disease (GERD), and the final model for smoking cessation counseling retained the variable for percentage of visits with a primary clinician.

In multivariate analyses, we found a statistically significantly lower likelihood of receiving cervical cancer screening with a Pap test $(\mathrm{RR}=0.60 ; 95 \% \mathrm{CI}, 0.47$ $0.76)$ and colorectal cancer screening $(\mathrm{RR}=0.42 ; 95 \%$ $\mathrm{CI}, 0.22-0.80)$ for patients on COT compared with patients not on COT. This effect was also observed for lipid screening ( $\mathrm{RR}=0.77 ; 95 \% \mathrm{CI}, 0.54-1.10)$, but did not reach statistical significance. The relative risk was not notably reduced for smoking cessation counseling $(\mathrm{RR}=0.95 ; 95 \% \mathrm{CI}, 0.78-1.15)$.

\section{DISCUSSION}

We found that patients receiving COT were significantly less likely to receive a Pap test or to receive any form of colorectal cancer screening. Although patients 


\begin{tabular}{|c|c|c|c|c|c|}
\hline \multicolumn{3}{|c|}{$\begin{array}{l}\text { Lipid Screening } \\
\quad(n=303)\end{array}$} & \multicolumn{3}{|c|}{$\begin{array}{l}\text { Smoking Counseling } \\
(n=298)\end{array}$} \\
\hline $\begin{array}{c}\text { COT } \\
(n=109)\end{array}$ & $\begin{array}{l}\text { Non-COT } \\
(n=194)\end{array}$ & $\begin{array}{c}P \\
\text { Value }^{a}\end{array}$ & $\begin{array}{c}\text { COT } \\
(n=101)\end{array}$ & $\begin{array}{l}\text { Non-COT } \\
(n=197)\end{array}$ & $\begin{array}{c}P \\
\text { Value }^{a}\end{array}$ \\
\hline 57.3 & 60.4 & .076 & 50.4 & 51.8 & .347 \\
\hline 61.5 & 58.2 & .584 & 64.4 & 65.5 & .847 \\
\hline 78.0 & 68.6 & .080 & 72.3 & 68.5 & .505 \\
\hline 4.6 & 5.7 & .686 & 5.9 & 5.6 & .900 \\
\hline 17.4 & 25.8 & .097 & 21.8 & 25.9 & .435 \\
\hline 31.2 & 42.8 & .047 & 16.8 & 37.1 & $<.001$ \\
\hline 34.9 & 24.7 & .061 & 51.5 & 32.0 & .001 \\
\hline 44.0 & 43.8 & .970 & 38.6 & 26.9 & .038 \\
\hline 7.3 & 6.2 & .698 & 8.9 & 16.2 & .082 \\
\hline 11.0 & 7.2 & .258 & 8.9 & 7.1 & .581 \\
\hline 18.3 & 7.2 & .003 & 27.7 & 17.9 & .049 \\
\hline 49.5 & 44.8 & .432 & 100.0 & 100.0 & $\mathrm{n} / \mathrm{a}$ \\
\hline 82.6 & 73.2 & .065 & 78.2 & 78.2 & .993 \\
\hline 15.6 & 7.2 & .021 & 15.8 & 11.2 & .252 \\
\hline 8.3 & 11.9 & .328 & 5.0 & 4.6 & .883 \\
\hline 46.8 & 28.9 & .002 & 49.5 & 36.5 & .031 \\
\hline 24.8 & 18.6 & .201 & 24.8 & 23.4 & .788 \\
\hline 9.2 & 2.6 & .011 & 5.9 & 3.6 & .340 \\
\hline 7.3 & 6.7 & .834 & 3.0 & 4.6 & .506 \\
\hline 5.5 & 1.0 & .020 & 5.9 & 4.1 & .468 \\
\hline 38.5 & 33.5 & .380 & 32.7 & 34.0 & .817 \\
\hline 28.2 & 27.2 & .531 & 29.1 & 29.1 & .994 \\
\hline 22.5 & 14.0 & $<.001$ & 23.8 & 14.3 & $<.001$ \\
\hline 82.5 & 82.0 & .858 & 81.1 & 75.9 & .064 \\
\hline 10.1 & 3.1 & .011 & 10.0 & 2.0 & .002 \\
\hline 28.4 & 29.9 & .789 & 61.4 & 56.9 & .452 \\
\hline
\end{tabular}

As previously noted, caring for patients with $\mathrm{CNCP}$ and prescribing opioids may be associated with time-consuming activities by clinicians, failures of the patient-physician relationship, and less time spent on preventive services. Patients on COT were more likely to have discontinued receiving care at the clinic, initiated by either the patient or the clinic, which might imply more challenging circumstances related to the patientclinician relationship. Furthermore, although our finding that COT patients were more likely to have a history of substance abuse might be an artifact of differential screening by clinicians, patients with such a history may be more likely to be preoccupied with obtaining opioids and less interested in other aspects of care.

We considered that the disparities we observed might result from greater medical complexity of these patients, aside from any challenges specific to CNCP and COT. In fact, for the 3 services that COT patients were less likely to receive, we found a significantly higher percentage of COT patients with 2 or more medical comorbidities. Despite these differences, however, the number of comorbidities was related only to colorectal cancer screening and even then was not significant in any regression models. Although it might be expected that a higher number of medical conditions would negatively affect quality of care, a recent study found the reverse was true. ${ }^{40}$ In contrast, another recent study found that patients on COT for $\mathrm{CNCP}$ received slightly worse diabetes care than patients not on COT. ${ }^{41}$

Our finding that patients with CNCP on COT had a higher number of clinic visits is consistent with other recent findings that chronic pain is associated with higher health care use. ${ }^{8}$ In our study, however, clinic visits actually lowered the likelihood of receiving preventive care. This finding is counter to the more intuitive notion that more clinic visits should lead to better preventive care because of more opportunities to provide that care. One explanation

on COT were also less likely to be screened for lipid disorders, this difference was not statistically significant. We did not find a difference in the likelihood of receiving counseling for smoking cessation. Our findings are consistent with the hypothesis that patients receiving COT may be less likely to receive certain preventive services. Our study does not elucidate the specific reasons or mechanisms that may underlie the disparities we found, but a number of possibilities warrant consideration. might be that until recently a US Drug Enforcement Administration policy limited opioid prescriptions to 30 days without refills, ${ }^{42}$ which made more frequent clinic visits necessary and added a time-consuming and inconvenient element to the management of chronic pain with opioids. Under these circumstances, clinical encounters might center on refilling opioid prescriptions and become somewhat ritualistic, to the exclusion of other elements of primary care. Another explanation might be that patients whose $\mathrm{CNCP}$ is 


\begin{tabular}{|c|c|c|c|}
\hline Preventive Service & $\begin{array}{l}\text { Unadjusted } \\
\text { RR }(95 \% \text { CI) }\end{array}$ & $\begin{array}{l}\text { Common Modela } \\
\text { RR }(95 \% \mathrm{Cl})\end{array}$ & $\begin{array}{l}\text { Final Model } \\
\text { RR }(95 \% \text { Cl) }\end{array}$ \\
\hline Cervical cancer screening & $0.72(0.57-0.92)$ & $0.60(0.47-0.76)$ & $0.60(0.47-0.76)$ \\
\hline Colorectal cancer screening & $0.57(0.29-1.09)$ & $0.48(0.25-0.91)$ & $0.42(0.22-0.80)$ \\
\hline Lipid screening & $0.95(0.66-1.37)$ & $0.77(0.54-1.10)$ & $0.77(0.54-1.10)$ \\
\hline Smoking counseling & $1.08(0.89-1.32)$ & $0.93(0.77-1.12)$ & $0.95(0.78-1.15)$ \\
\hline \multicolumn{4}{|c|}{$\mathrm{Cl}=$ confidence interval; $\mathrm{RR}=$ relative risk. } \\
\hline \multicolumn{4}{|c|}{ a Adjusted for age, clinic, and total number of clinic visits. } \\
\hline \multicolumn{4}{|c|}{$\begin{array}{l}\text { b Adjusted for age, clinic, and total number of clinic visits. In addition, the colorectal cancer screening model } \\
\text { adjusted for diagnosis of gastroesophageal reflux disease; and the smoking cessation counseling model } \\
\text { adjusted for percentage of visits with primary clinician. }\end{array}$} \\
\hline
\end{tabular}

most poorly controlled have the highest frequency of clinic visits. ${ }^{8}$ If so, it is possible that relatively more time would be spent addressing poorly controlled pain, thereby reducing the likelihood that preventive care would be addressed.

The effect of COT varied among the 4 preventive services. This might be explained by the greater time requirements, technical complexity, and logistical demands associated with Pap testing or colorectal cancer screening, which could make receipt of these services more sensitive to time-consuming activities related to COT and CNCP. In addition, compared with lipid screening or smoking cessation counseling, discussing or performing a Pap test or colorectal cancer screening may require a higher degree of trust and comfort, which might be compromised if the patientphysician relationship were strained.

Our results should be viewed with several other considerations in mind. Although chart auditors were not blinded to COT status or the research question, we took various measures to assure a high-quality, reliable record review. The auditors received training in a standardized protocol, explicit written data abstraction criteria, explicit variable definitions, and a standardized data abstraction form. Furthermore, they reviewed charts in an order unrelated to COT status and abstracted most variables, including the preventive services outcomes, months after the initial abstraction to determine COT status, thereby possibly buffering their awareness of individual patients' COT status while abstracting most data.

The preventive service outcomes were defined as at least 1 occurrence during the 3 -year study period, not as up-to-date status. For certain services, a large baseline difference in up-to-date status between COT and non-COT patients might explain some or all of the observed difference in receipt of the service during the 3 study years that followed. A baseline dif- ference would not affect Pap testing, which is recommended, because all eligible women would be expected to receive screening at some time during the 3 -year study period. The screening frequency for colorectal cancer can be up to 10 years, and the relative shortness of our 3-year study period is likely to be a factor in the overall low percentages of colorectal cancer screening seen in this study. That said, more than twice as many COT patients as non-COT patients would have to have been up-to-

date at baseline to explain the difference we observed which seems unlikely. Similarly, for lipid screening at a suggested frequency of 5 years, ${ }^{43}$ approximately $23 \%$ more COT than non-COT patients would have been up-to-date at baseline to explain the difference we observed, which also seems unlikely. A baseline difference would not be expected to affect smoking cessation counseling, which is generally brief and recommended at every opportunity.

Finally, it is not clear whether our findings are due to COT alone, an effect of patients' pain, or a combination of the two. We did not adjust for a possible effect of pain distinct from COT status. CNCP and COT may each influence the clinical encounter and preventive care in similar and different ways. Patients with CNCP may have little interest in preventive services, particularly those associated with physical discomfort, unless their pain is adequately addressed. Adjustment for patients' general pain level and pain level at the time of clinic visits might distinguish the unique effects of pain and COT.

In this study, conducted in 7 rural primary care practices, patients receiving COT for CNCP were less likely to receive screening for cervical or colorectal cancer. Our findings suggest that providing appropriate preventive services for these patients may present particular challenges that current systems of care are not meeting. We believe that future research to better characterize the relationship between COT, CNCP, and preventive care could inform changes in practice and systems of care to more effectively provide preventive services. Future studies could use qualitative methods to more clearly understand the characteristics of patients, clinicians, clinics, and clinical encounters that affect the quality of preventive care received by patients with this common chronic problem.

To read or post commentaries in response to this article, see it online at http://www.annfammed.org/cgi/content/full/8/3/237. 
Submitted July 28, 2009; submitted, revised, November 20, 2009; accepted December 2, 2009.

Key words: Primary health care; family practice; rural health care; preventive services; health disparities; chronic pain; opioid therapy; practice-based research; health services research

Funding support: This study was supported by a grant from the American Academy of Family Physicians Foundation (grant No. G0417). Dr Calvert received salary support for the study from The Merle West Center for Medical Research, Klamath Falls, Oregon. The Oregon Rural Practice-based Research Network receives support from a Clinical and Translational Science Award to Oregon Health \& Science University (NIH/NCRR 1 U1 RR02414-01)

Findings of this study were presented in part at the annual meeting of the North American Primary Care Research Group, Vancouver, British Columbia, October, 2007; the annual Convocation of Practices and Networks, American Academy of Family Physicians, National Research Network and Federation of Practice Based Research Networks (plenary presentation), Colorado Springs, Colorado, March, 2008; the annual Convocation of Practices, Oregon Rural Practiced-based Research Network, Portland, Oregon, April, 2008; and the 25th Annual Oregon Rural Health Conference, Bend, Oregon, September, 2008.

Acknowledgments: We acknowledge the 7 Oregon Rural Practicebased Research Network (ORPRN) practices that participated in this study: Cascades East Family Practice; Klamath Open Door Family Medicine; La Clinica del Carino Family Health Center; Lincoln City Medical Center; Rinehart Clinic; Strawberry Wilderness Family Clinic; and Union Family Health Center. We acknowledge ORPRN's practice enhancement research coordinators, Ann Ford, Monica Goubaud, and Julie Reynolds, for their invaluable on-site management and field work. We thank Anne King, James Wallace, Heather Angier, and Mary Masterson for their skillful administrative assistance. We thank Judy Logan, MD, MS, for her assistance with data management. We thank Lyle Fagnan, MD, and Richard Deyo, MD, MPH, for their valuable comments and suggestions.

\section{References}

1. Elliott AM, Smith BH, Penny KI, Smith WC, Chambers WA. The epidemiology of chronic pain in the community. Lancet. 1999;354 (9186):1248-1252.

2. Gallagher RM. Primary care and pain medicine. A community solution to the public health problem of chronic pain. Med Clin North Am. 1999;83(3):555-583.

3. Glajchen M. Chronic pain: treatment barriers and strategies for clinical practice. J Am Board Fam Pract. 2001;14(3):211-218.

4. Reid MC, Engles-Horton LL, Weber MB, Kerns RD, Rogers EL, O'Connor PG. Use of opioid medications for chronic noncancer pain syndromes in primary care. J Gen Intern Med. 2002;17(3):173-179.

5. Stewart WF, Ricci JA, Chee E, Morganstein D, Lipton R. Lost productive time and cost due to common pain conditions in the US workforce. JAMA. 2003;290(18):2443-2454

6. National Center for Health Statistics. Health, United States, 2006: With Chartbook on Trends in the health of Americans. Hyattsville, MD: US Centers for Disease Control and Prevention, NCHS; 2006.

7. Bertakis KD, Azari R, Callahan EJ. Patient pain: its influence on primary care physician-patient interaction. Fam Med. 2003;35(2): 119-123.

8. Blyth FM, March LM, Brnabic AJM, Cousins MJ. Chronic pain and frequent use of health care. Pain. 2004;111(1-2):51-58.
9. Clark JD. Chronic pain prevalence and analgesic prescribing in a general medical population. J Pain Symptom Manage. 2002;23(2): 131-137.

10. Smith BH, Elliott AM, Hannaford PC; Royal College of General Practitioners' Oral Contraception Study. Is chronic pain a distinct diagnosis in primary care? Evidence arising from the Royal College of General Practitioners' Oral Contraception study. Fam Pract. 2004;21(1):66-74.

11. Noble M, Tregear SJ, Treadwell JR, Schoelles K. Long-term opioid therapy for chronic noncancer pain: a systematic review and metaanalysis of efficacy and safety. J Pain Symptom Manage. 2008;35(2): 214-228.

12. Chou R, Ballantyne JC, Fanciullo GJ, Fine PG, Miaskowski C. Research gaps on use of opioids for chronic noncancer pain: findings from a review of the evidence for an American Pain Society and American Academy of Pain Medicine clinical practice guideline. J Pain. 2009;10(2):147-159.

13. Ballantyne JC, Mao J. Opioid therapy for chronic pain. N Engl J Med. 2003;349(20):1943-1953.

14. Passik SD, Weinreb HJ. Managing chronic nonmalignant pain: overcoming obstacles to the use of opioids. Adv Ther. 2000;17(2):70-83.

15. Potter M, Schafer S, Gonzalez-Mendez E, et al. Opioids for chronic nonmalignant pain. Attitudes and practices of primary care physicians in the UCSF/Stanford Collaborative Research Network. University of California, San Francisco. J Fam Pract. 2001;50(2):145-151.

16. Harden RN. Chronic pain and opiates: a call for moderation. Arch Phys Med Rehabil. 2008;89(3)(Suppl 1):S72-S76.

17. Højsted J, Sjøgren P. An update on the role of opioids in the management of chronic pain of nonmalignant origin. Curr Opin Anaesthesiol. 2007;20(5):451-455.

18. Ballantyne JC. Opioids for chronic nonterminal pain. South Med J. 2006;99(11):1245-1255.

19. Devulder J, Richarz U, Nataraja SH. Impact of long-term use of opioids on quality of life in patients with chronic, non-malignant pain. Curr Med Res Opin. 2005;21(10):1555-1568.

20. Furlan AD, Sandoval JA, Mailis-Gagnon A, Tunks E. Opioids for chronic noncancer pain: a meta-analysis of effectiveness and side effects. CMAJ. 2006;174(11):1589-1594.

21. Nwokeji ED, Rascati KL, Brown CM, Eisenberg A. Influences of attitudes on family physicians' willingness to prescribe long-acting opioid analgesics for patients with chronic nonmalignant pain. Clin Ther. 2007;29(Suppl):2589-2602.

22. Savage SR. Assessment for addiction in pain-treatment settings Clin J Pain. 2002;18(4)(Suppl):S28-S38.

23. Lin JJ, Alfandre D, Moore C. Physician attitudes toward opioid prescribing for patients with persistent noncancer pain. Clin J Pain 2007;23(9):799-803.

24. Bhamb B, Brown D, Hariharan J, Anderson J, Balousek S, Fleming MF. Survey of select practice behaviors by primary care physicians on the use of opioids for chronic pain. Curr Med Res Opinion. 2006;22(9):1859-1865.

25. Fields HL. Should we be reluctant to prescribe opioids for chronic non-malignant pain? Pain. 2007;129(3):233-234.

26. Bendtsen P, Hensing G, Ebeling C, Schedin A. What are the qualities of dilemmas experienced when prescribing opioids in general practice? Pain. 1999;82(1):89-96.

27. Gallagher RM. Opioids in chronic pain management: Navigating the clinical and regulatory challenges. J Fam Pract. 2004;53(10) (Suppl):S23-S32.

28. Jung B, Reidenberg MM. Physicians being deceived. Pain Med. 2007;8(5):433-437.

29. Edlund MJ, Sullivan M, Steffick D, Harris KM, Wells KB. Do users of regularly prescribed opioids have higher rates of substance use problems than nonusers? Pain Med. 2007;8(8):647-656. 
30. Crane M. Treating pain: damned if you don't? Med Econ. 2001; 78(22):66-68.

31. Fishman S, Papazian J, Gonzalez S, Riches P, Gilson A. Regulating opioid prescribing through prescription monitoring programs: balancing drug diversion and treatment of pain. Pain Med. 2004; 5(3):309-324

32. Ponte CD, Johnson-Tribino J. Attitudes and knowledge about pain: an assessment of West Virginia family physicians. Fam Med. 2005;37(7):477-480.

33. Green CR, Wheeler JR, Marchant B, LaPorte F, Guerrero E. Analysis of the physician variable in pain management. Pain Med. 2001; 2(4):317-327.

34. Bradley CP. Decision making and prescribing patterns-a literature review. Fam Pract. 1991;8(3):276-287.

35. Bradley CP. Factors which influence the decision whether or not to prescribe: the dilemma facing general practitioners. Br J Gen Pract. 1992;42(364):454-458

36. McNutt L-A, Wu C, Xue X, Hafner JP. Estimating the relative risk in cohort studies and clinical trials of common outcomes. Am J Epidemiol. 2003;157(10):940-943.

37. Zhang J, Yu KF. What's the relative risk? A method of correcting the odds ratio in cohort studies of common outcomes. JAMA. 1998; 280(19):1690-1691.
38. Spiegelman D, Hertzmark E. Easy SAS calculations for risk or prevalence ratios and differences. Am J Epidemiol. 2005;162(3):199-200.

39. Zou G. A modified poisson regression approach to prospective studies with binary data. Am J Epidemiol. 2004;159(7):702-706.

40. Higashi T, Wenger NS, Adams JL, et al. Relationship between number of medical conditions and quality of care. $N$ Engl J Med. 2007;356(24):2496-2504.

41. Rose AJ, Hermos JA, Frayne SM, Pogach LM, Berlowitz DR, Miller DR. Does opioid therapy affect quality of care for diabetes mellitus? Am J Manag Care. 2009;15(4):217-224.

42. Drug Enforcement Administration. Office of Diversion Control, US Department Of Justice Issuance of Multiple Prescriptions for Schedule II Controlled Substances. http://www.deadiversion.usdoj. gov/fed_regs/rules/2007/fr1119.htm. Accessed Jul 27, 2009.

43. US Preventive Services Task Force (USPSTF), Agency for Healthcare Research and Quality. Guide to Clinical Preventive Services: Recommendations of the US Preventive Services Task Force. http://www.ahrq gov/clinic/uspstfix.htm. Accessed Jul 27, 2009. 